University of Nebraska - Lincoln

DigitalCommons@University of Nebraska - Lincoln

\title{
Oviducal Sperm Storage in Turkeys: Spatial Distribution of Sperm Within the Uterovaginal Junction Sperm-Storage Tubules
}

\author{
M. R. Bakst \\ USDA, murray@anri.barc.usda.gov \\ Bryan T. Vinyard \\ United States Department of Agriculture
}

Follow this and additional works at: https://digitalcommons.unl.edu/usdaarsfacpub

Part of the Agricultural Science Commons

Bakst, M. R. and Vinyard, Bryan T., "Oviducal Sperm Storage in Turkeys: Spatial Distribution of Sperm Within the Uterovaginal Junction Sperm-Storage Tubules" (2002). Publications from USDA-ARS / UNL Faculty. 630.

https://digitalcommons.unl.edu/usdaarsfacpub/630

This Article is brought to you for free and open access by the U.S. Department of Agriculture: Agricultural Research Service, Lincoln, Nebraska at DigitalCommons@University of Nebraska - Lincoln. It has been accepted for inclusion in Publications from USDA-ARS / UNL Faculty by an authorized administrator of DigitalCommons@University of Nebraska - Lincoln. 


\title{
Oviducal Sperm Storage in Turkeys: Spatial Distribution of Sperm Within the Uterovaginal Junction Sperm-Storage Tubules
}

\author{
MURRAY R. BAKST ${ }^{1 *}$ AND BRYAN T. VINYARD ${ }^{2}$ \\ ${ }^{1}$ Germplasm and Gamete Physiology Laboratory, Agricultural Research \\ Service, U.S. Department of Agriculture, Beltsville, Maryland 20705-2350 \\ ${ }^{2}$ Biometrical Consulting Service, Agricultural Research Service, U.S. \\ Department of Agriculture, Beltsville, Maryland 20705-2350
}

\begin{abstract}
The spatial distribution of sperm within the sperm storage tubules (SST) found in the uterovaginal junction (UVJ) of the turkey is not known. In this study, we inseminated sperm stained with a fluorescent dye (Hoechst 33342) to determine their distribution in SST in the ventral, dorsal, and lateral regions of the proximal, middle, and distal regions of the UVJ. There was no preferential filling in the ventral-dorsal axis of the UVJ. In contrast, preferential filling of the SST was observed in the middle section of the UVJ. Here the individual SST were clearly longer and more pleomorphic than the SST in the more proximal and distal aspects of the UVJ. While no information on the temporal aspect of SST filling by sperm could be gleaned, it is evident that the more morphologically developed SST either accept sperm more readily or store sperm more efficiently than SST elsewhere in the UVJ. J. Exp. Zool. 292:206-209, 2002. (c) 2002 Wiley-Liss, Inc.
\end{abstract}

The capacity of hens to lay a succession of fertile eggs is, in part, based on the capacity to store sperm in the oviduct. Depending on the species, sperm can reside in the sperm storage tubules (SST) for a few days to 10 weeks following mating or artificial insemination. Anatomically, the SST are specialized simple tubular invaginations of the uterovaginal junction (UVJ) epithelium composed of simple columnar, nonsecretory cells. Although the object of numerous studies, the processes involved in sperm uptake, maintenance, and release from SST remain unknown.

In the turkey, only the left ovary and oviduct develop into functional organs. At sexual maturation, the largest in the hierarchy of follicular oocytes ovulates generally between 30 and 60 minutes after oviposition. This ovulated ovum is grasped by the fimbriated region of the oviduct and is guided toward the ostium of the infundibulum, the most anterior segment of the avian oviduct. If sperm are present in the infundibulum the ovum may be fertilized. The formed egg is laid $26 \mathrm{hr}$ later. This $26-\mathrm{hr}$ cycle, from ovulation to oviposition, is referred to as the daily ovulatory cycle. In the modern day turkey industry, hens are artificially inseminated (AI) weekly with 200 million to 300 million sperm. From this single insemination, hens may lay a daily succession of fertile eggs. The capacity to lay such a succession of fertile eggs is only possible because of the ability of the hen to store sperm in her oviduct. More thorough reviews of oviducal sperm storage in birds are found in papers by Bakst et al. ('94) and Bakst ('98).

We actually know very little about the dynamics of sperm filling of the SST except that maximum filling following AI takes about $48 \mathrm{hr}$ in the turkey (Brillard and Bakst, '90; Brillard, '93) and $24 \mathrm{hr}$ in the chicken (Brillard, '93). Several investigators have attempted to estimate sperm numbers and the spatial distribution of the sperm within the SST (Bakst et al., '94). Histological procedures provided some insight into the spatial distribution of sperm in the SST; however, the actual number of sperm residing in the SST was estimated by other procedures. These included the following: moderate grinding (Brillard and Bakst, '90), collagenase digestion (Brillard, '93), and/or homogenization of the SST (McLean and Froman, '96). These procedures were useful for the determination of overall sperm numbers in the UVJ but told us nothing about the sperm numbers within the individual SST.

*Correspondence to: M.R. Bakst, Germplasm and Gamete Physiology Laboratory, Bldg. 200, Powder Mill Road, USDA-ARS, Beltsville, Maryland 20705-2350. E-mail: murray@anri.barc.usda.gov

Received 14 September 2001; Accepted 14 September 2001 
Hoechst 33342 (bisbenzamide), a fluorescent dye that binds to the DNA of living cells, was first used by Bakst ('94) to improve visualization of sperm within the SST and infundibulum. That provided an opportunity for a qualitative assessment of the differential filling rates of SST in preand post-lay turkey hens. More recent work by King et al. (2002) using tandem inseminations with stained and unstained sperm, showed that there was little evidence of stratification of sperm from successive inseminations in the SST. Thus, the theorized last-male precedence in paternity does not appear to be due to the stratification of sperm within the SST. In the course of doing this work, we questioned whether there may have been regional differences in the rate of filling of the SST with sperm. In the current study, we determined if there is a preferential filling of the SST in different regions of the UVJ. Both anterior-posterior and dorsal-ventral orientations of the UVJ were examined.

\section{MATERIALS AND METHODS}

Large White breeder turkeys (British United Turkeys of America, West Virginia) were maintained in environmentally controlled houses on a 14:10 light:dark photoperiod and housed individually either in cages (hens) or in groups of 8 to 10 in pens (males). Feed and water were provided ad libitum. Semen was collected weekly from 30 weeks of age to the beginning of this study. At 40-45 weeks of age, pooled semen samples were stained prior to inseminations with Hoechst 33342 $(90 \mathrm{nM})$ according to the procedure of Bakst ('94). In order to minimize the impact of inseminating hens at different times of their ovulatory cycle, all hens were inseminated within one hour after oviposition with a single deep $(4-6 \mathrm{~cm})$ intravaginal insemination of about 250 million sperm.

Eleven hens were euthanized by cervical dislocation $48 \mathrm{hr}$ after insemination. The uterus and vagina were isolated, the dorsal ligament marked, and the connective tissue enveloping the vagina and uterus removed by methods reviewed elsewhere (Bakst, '94). The UVJ luminal muscosa, including the distal uterine and proximal vaginal muscosa, was exposed by a longitudinal cut along the dorsal oviductal ligament.

Starting at the cut edge at the dorsal oviductal ligament, the UVJ mucosa was divided into four equally spaced longitudinal segments, 1-2 mucosal folds wide. At each quadrant, folds were excised as described previously to visualize the SST (Brillard and Bakst, '90) and labeled as folds 1, 2,
3 , and 4. Each fold was examined by stereo microscopy, and the UJV containing SST was further divided into the proximal (Px), middle (Mid) and distal (Dt) regions.

To determine the presence or absence of sperm in the SST, each of the 12 mucosal samples per hen was prepared as a squash preparation. For each specimen slide, the presence or absence of sperm in randomly chosen microscopic fields was determined by fluorescence microscopy $(40 \times$ objective). One or more sperm in any portion of the SST was designated in the "yes" category. These data were subjected to a logistic regression and significant differences were identified by general ANOVA and pairwise contrast likelihood ratio tests on generalized logits using Proc Logistic in SAS Version 8 (Stokes et al., '95). The likelihood ratio test is similar to a chi square but more robust.

\section{RESULTS}

ANOVA (Table 1) indicated that there was no significant interaction between the UVJ regions (Px, Mid, Dt) and the four equidistant folds of the UVJ $(P=.32)$ and consequently, all the fold data were combined and examined. As shown in Table 2 , the largest proportion of sperm-containing SST is in the Mid region (65\%), followed by the Px (59\%) and Dt UVJ regions (54\%). Interestingly, the Mid region is populated almost exclusively by SST that appear to be fully morphologically developed. That is, individual SST may be pleomorphic (highly coiled or convoluted or relatively straight) in character and up to $300 \mu \mathrm{m}$ in length. The SST at the Dt region were considerably shorter and straighter, and those at the Px region were also shorter and did not appear to be as dense (possibly less lipid in the SST epithelial cells) as the Mid and Dt regions.

\section{DISCUSSION}

This work shows that the SST in the Mid region of the UVJ are filled by sperm and/or sperm are retained more efficiently than in the Px and Dt regions of the UVJ. Furthermore, gravity or unique "tracts" for transport of sperm (Mimura,

TABLE 1. Analysis of position and fold SST data: ANOVA table using log likelihood ratio test

\begin{tabular}{lccc}
\hline Source & df & LLDiff* & P-value \\
\hline Region & 2 & 94.4 & 0.0001 \\
Fold & 3 & 5.27 & 0.15 \\
Region x Fold & 6 & 6.94 & 0.32 \\
\hline
\end{tabular}

*Log likelihood difference. 
TABLE 2. Presence (YES) or absence (NO) of sperm in SST from the proximal, middle, and distal regions of the UVJ

\begin{tabular}{lllc}
\hline & \multicolumn{1}{c}{ SST } & \multicolumn{1}{c}{ SST } & \\
Regions & YES $(\%)$ & NO $(\%)$ & Total SST \\
\hline Proximal & $2199(59)^{\mathrm{a}}$ & $1551(41)$ & 3750 \\
Middle & $2447(65)^{\mathrm{b}}$ & $1303(35)$ & 3750 \\
Distal & $2038(54)^{\mathrm{c}}$ & $1712(46)$ & 3750 \\
TOTAL & 6684 & 4566 & 11250 \\
\hline
\end{tabular}

Within columns, different letters indicate significant differences $(P$ $<.05)$.

'39) did not influence the distribution of sperm in the any of the UVJ regions. The spatial location of the SST, that is whether a fold is more dorsal or ventral, is not a significant factor in the disposition of the sperm within the SST. Interestingly, the longest and seemingly most morphologically differentiated SST, which were dominant in the Mid region, were also the most likely to contain any sperm. This suggests that either the mechanisms for sperm entry into the SST are more efficient in this region or sperm egress from the shorter SST in the Px and Dt regions is more rapid.

An important question that remains unanswered is the temporal order, if any, of sperm entering the SST relative to the location of the SST within the UVJ. Do sperm first enter the Dt region of the SST then progressively fill the more proximal regions of the UVJ with each insemination or copulation? J.P. Brillard (personal communication) speculated that if this does transpire, it could be the basis for the observed sperm precedence in fertilization. He suggested that the observed "first in-last out" precedence for fertilization (Compton et al., '78) may not be due to stratification of sperm within individual SST but a stratification of sperm within the UVJ. When a virgin hen is first inseminated or copulates, the sperm that reach the UVJ may preferentially enter the SST located in the Dt region of the UVJ. It was further hypothesized that, with subsequent inseminations, sperm fill the SST progressively toward the proximal end of the UVJ and, to a lesser extent, add to the SST containing sperm from earlier inseminations. It is these sperm, those filling the more proximal SST, that are then released more readily and preferentially than the sperm from the earlier inseminations. Unfortunately, our data do not afford additional insight into this question. However, it does support the "passive sperm loss" theory of sperm egress from the SST suggested by Birkhead and Biggins ('97). Furthermore, this model of SST filling and replenishment by sperm with successive inseminations supports unpublished observa- tions from this laboratory (King et al., 2002) Inseminations of stained, followed by unstained, sperm and subsequent examination of sperm distribution in the SST of turkey hens revealed the absence of significant stratification of sperm in all but $12 \%$ of the SST examined. Thus, it was theorized that the last-male precedence does not appear to be due to the stratification of sperm within the SST of fowl or turkey hens.

To conclude, the capacity to store sperm affords to the female bird the following: eliminates the need for synchronization of copulation with ovulation; sperm transfer to hen is not necessary for production of fertile eggs over one or more clutches; provides reservoir for selected sperm; and affords protection to sperm during the daily ovulatory cycle. Our knowledge of these processes-how the sperm are "selected" for storage in the SST, how these sperm enter the SST, survive within the SST, and exit from the SSTremain elusive. However, a few significant observations have provided some insight into the possible biological mechanisms of these phenomena. For example, highly fecund toms posses the most mobile sperm, and it is assumed that this "mobility" enhances selection of their sperm for transport to the UVJ after AI (Donoghue, '99). Recent observations by Freedman et al. (2001) revealed that the SST are innervated and led to the suggestion that a neural mechanism may function in the release of sperm from the SST. Once the biological basis for sperm selection and storage is understood, our ability to store sperm in vitro will be vastly improved. Not only does this have implications for the poultry industry, but also it could also impact our ability to store germplasm and further propagate endangered avian species.

\section{LITERATURE CITED}

Bakst MR. 1994. Fate of fluorescent stained sperm following insemination: New light on oviducal sperm transport and storage in the turkey. Biol Reprod 50:987-992.

Bakst MR. 1998. Structure of the avian oviduct with emphasis on sperm storage in poultry. J Exp Zool 282:618-626.

Bakst MR, Wishart G, Brillard JP. 1994. Oviducal sperm selection, transport, and storage in poultry. Poult Sci Rev 5:117-143.

Birkhead TR, Biggins JD. 1997. Sperm competition mechanisms in birds: models and data. Behav Ecol 9:253-260.

Brillard JP. 1993. Sperm storage and transport following natural mating and artificial insemination. Poult Sci 71:923-928.

Brillard JP, Bakst MR. 1990. Quantification of spermatozoa in the sperm-storage tubules of turkey hens and the relation of sperm numbers in the perivitelline layer of eggs. Biol Reprod 43:271-275.

Compton MM, Van Krey HP, Siegel PB. 1978. The filling and 
emptying of the uterovaginal sperm-host glands in the domestic hen. Poult Sci 57:1696-1700.

Donoghue AM. 1999. Prospective approaches to avoid future flock fertility problems: Predictive assessment of sperm function traits in poultry. Poult Sci 78:437-443.

Freedman S, Akuffo V, Bakst MR. 2001. New evidence for the innervation of the sperm storage tubules in the turkey (Meleagris Gallopavo). Reprod 121:809-814.
McLean DJ, Froman DP. 1996. Identification of a sperm cell attribute responsible for subfertility of roosters homozygous for the rose comb allele. Biol Repro 54:168-172.

Mimura H. 1939. On the mechanism of travel through the oviduct in the domestic fowl, with special reference to artificial insemination. Okajimas Folia Anat Jap 17:459-471.

Stokes ME, Davis CS, Koch GG. 1995. Categorical data analysis using the SAS system. Cary, NC: SAS Institute Inc. 